\title{
Long-term results of the first line DMT depend on the presence of minimal MS activity during first years of therapy: data of 15 years observation
}

\author{
A. Boyko ${ }^{*}$ on behalf of neurologists of the Moscow MS Center
}

\begin{abstract}
Background: There are still few prospective longitudinal studies of DMT in MS that show long-lasting effects. Methods: The data of longitudinal observation for 15 years on a group of 69 MS patients constantly receiving glatiramer acetate (GA) are presented.

Results: The increase in relapse rate and EDSS progression were associated in a subgroup of patients with the presence of at least one relapse during the first 5 years of observation.

Conclusion: Only total absence of clinical activity, according to NEDA definition, during at least the first 5 years of therapy might be classified as the "optimal" response to GA.
\end{abstract}

\section{Background}

Multiple sclerosis (MS) is a lifelong and progressive disease. Accordingly, it is important to prospectively collect data on the long-term benefits of its treatments. Betainterferons and Glatiramer acetate (GA) are still used as the first line therapy for relapsing remitting multiple sclerosis (RRMS). These medications can potentially modify the clinical course of the disease. Double blind randomized clinical studies showed that diseasemodifying treatments (DMT) significantly reduces relapse rate as well as the number of new/enlarged lesions on MRI [1]. Influence of DMT on disability progression was among studies less evident.

Although MS is a long lasting disease, most of these studies were relatively short in duration and evidence of long-term clinical efficacy, safety and patient adherence to DMT is frequently missing. The definition of the modern criteria "no evidence of disease activity" in MS (NEDA) includes no relapses, no disability progression and no new/enlarging lesions on MRI for NEDA-3, plus no brain atrophy progression for NEDA-4 [2]. This

Correspondence: boykoan13@gmail.com

Department of Neurology, Neurosurgery and Clinical Genetic of the Russian State Medical University \& MS Center, Moscow, Russia definition is strongly connected with the determination of "optimal", "sub optimal" and "not optimal" response to selected DMT. A recent study from USA (Boston) showed that only $46 \%$ had NEDA for clinical and MRI measures at 1 year and only $7.9 \%$ - maintained NEDA status after 7 years. NEDA at 2 years had a positive predictive value of $78.3 \%$ for no progression [3]. A more recent study showed that only 8 of 91 MS patients $(8 \%)$ maintained NEDA for 9.3-12.5 years of observation [4]. Both studies did not analyze the route of treatment of these patients and it is not known, if they received any DMT or what was the natural course of their demyelinating disease.

Due to high costs and long duration of the DMT, long-term prospective observations on DMT efficacy are highly needed. However such studies can be difficult to perform due to multiple social, economical and medical factors. Here we present results of a 15-years open-label un-randomized observational study of glatiramer acetate (GA) therapy in RRMS patients of the Moscow MS Center. Results of the 3,5 and 10-year observations have been previously published [5-7]. The rational of this observational study was to assess long-term efficacy of GA by recording significant clinical information (decrease in annual relapse rate (ARR) and slowing the 
EDSS progression), during their treatment with this first-line DMT in patients with "optimal" clinical treatment response who continued the selected therapy at least for 15 years.

\section{Methods}

In 2000, 205 very active relapsing-remitting multiple sclerosis (RRMS) patients, diagnosed according to the Poser clinical criteria [8], started therapy with GA at the Moscow MS Centre. At baseline they had an annual relapse rate (ARR) of 2.15 and an EDSS score between 1.5 and 5.0 (median 2.15, mean 2.11). Corticosteroids, plasmapheresis and other symptomatic treatments of relapses had been used, but no DMT. At baseline all patients (100\%) had active Gd + -lesions on brain MRI and the number of the T2-lesions in all cases were higher than 10 (these criteria had to be met in Russia to receive DMT for free). Accordingly, this was a subgroup of very active relapsing-remitting MS patients. All patients were regularly observed at 3 month intervals and/or in cases of relapses and detailed neurological examination, including Expanded Disability Status Scale (EDSS) levels, were recorded in the Register of the Moscow MS Center (MMSC). Patients gave informed consent to be included into the study. Patients with other concomitant neurological conditions, psychiatric diseases or pregnancy were excluded. Over time, further MRI imaging was obtained using different equipment and could not be compared.

At 3 years 155/205 patients (75.6\%) continued to receive $\mathrm{GA}$; reasons for the loss at follow-up are listed in Table 1. Clinical failure (high relapse rate, EDSS progression or change to secondary progressive MS - SPMS) were seen in 37 patients (18\%); 8 patients (4\%) had problems with tolerability; 5 patients $(2 \%)$ were lost to observation for other reasons.
After 5 years, $59 \%$ of the patients were still under observation, while $28 \%$ discontinued GA due to treatment failure. After 10 years and 15 years the majority of patients were still under observation, the number of treatment failures and patients with tolerability problems were small, while up to $5 \%$ had to discontinued this DMT for other reasons (migration, death, pregnancy, etc). A total of 74 patients continued to receive exclusively GA treatment over 10 years up to the intermediate 10 years analysis [7]. All these patients were then observed for the following additional 5 years (15 years overall). One patient stopped the treatment because of the onset of a secondary progression (SPMS), 1 was tired of frequent injections, 2 of them were disregarded because of the lack of detailed information, 1 died in a car accident. The remaining extendedly observed 69 patients (50 females - $72.5 \%$ ) showed a mean age 33.0 (0.9) years and mean MS duration of 5.43 (0.44) years. Almost half of these MS patients suddenly progressed in EDSS after a period of high annualized relapse rate (ARR) between years 12 and 13 and only 35 of them still continued GA therapy after 15 years of uninterrupted treatment.

As recommended, all patients received GA $20 \mathrm{mg} /$ day SC. Clinical outcome measures of efficacy were ARR and EDSS score. Increase in EDSS level was confirmed if not decreasing for at least for 6 months. Statistical analysis was performed with the STATISTICA program. Data are presented as Mean (SD). To determine the differences between two subgroups, the Student's $t$-test was used for continuous variables and the Fisher Exact test was used for categorical variables, $p$ values $<0.05$ were considered significant. Pearson's correlation analysis was performed to estimate the association between parameters. The effects of treatment on ARR and EDSS score from baseline to year 15 (dichotomous model

Table 1 The data of dynamic observation of 205 MS patients, started GA therapy in 2000

\begin{tabular}{|c|c|c|c|c|c|}
\hline \multirow[t]{2}{*}{ Time } & \multirow{2}{*}{$\begin{array}{l}\text { Treated } \\
\text { Started }\end{array}$} & \multicolumn{4}{|c|}{ Discontinued the GA therapy } \\
\hline & & Continues & $\begin{array}{l}\text { Clinical failure (including change } \\
\text { to SPMS course) }\end{array}$ & Tolerability and side effects & $\begin{array}{l}\text { Others (including pregnancies, } \\
\text { deaths, migration, escaping } \\
\text { from observation, etc.) }\end{array}$ \\
\hline Baseline & 205 & & & & \\
\hline \multirow[t]{2}{*}{3 years } & & $155(76 \%)$ & $37(18 \%)$ & $8(4 \%)$ & $5(2 \%)$ \\
\hline & 155 & & & & \\
\hline \multirow[t]{2}{*}{5 years } & & $91(59 \%)$ & $42(28 \%)$ & $12(8 \%)$ & $7(5 \%)$ \\
\hline & 91 & & & & \\
\hline \multirow[t]{2}{*}{10 years } & & $74(81 \%)$ & $10(11 \%)$ & $2(2 \%)$ & $5(3 \%)$ \\
\hline & 74 & & & & \\
\hline \multirow[t]{3}{*}{15 years } & & $69(93 \%)$ & $1(1 \%)$ & $1(\%)$ & $3(5 \%)$ \\
\hline & 69 & & & & \\
\hline & Continues 35 & Stopped 34 & & & \\
\hline
\end{tabular}


with 0 - continued therapy, 1- stopped therapy) in groups of patients defined by demographic and disease characteristics were compared using logistic regression with a significance level of 0.05 .

The study was approved by the Ethical Committee of the Pirogov's RNRMU and was in compliance with the Helsinki Declaration.

\section{Results}

Before initiation of GA treatment (baseline) ARR was elevated - 2.15 (0.06) per year (Table 2), but these patients had a relatively low EDSS score of 2.11 (0.10). Accordingly, this subgroup of patients had active relapsing MS with low accumulation of disability.

\section{Relapse rates}

When GA was started all patients showed a significant reduction of ARR which remained quite stable throughout the course of the follow-up. Mean ARR declined from $2.15(0.06)$ at baseline down to $0.06-0.08$ in the first 3 years of therapy, but it slowly increased to a mean level of $0.17(0.05)$ at year 7 and at year 14, to 0.18 $(0.05)$ at year 11 and up to 0.21 at year 13 (Fig. 1 green line). Mean ARR for all patients for the entire 15-year period was 0.14 per year. No baseline demographic characteristics were associated with ARR or GA discontinuation after 15 years of therapy in this subgroup of patients.

\section{Disability progression}

Mean EDSS score slowly progressing during the 15-year period is shown in Fig. 2 (green line). A slight reduction of EDSS in the first and second year of treatment was recorded but found not to be significant. Conversely, a significant increase in the EDSS was seen at years 11-15 and up to the mean level of $3.26(0.18)$ at year 15 . In 7 patients (10.1\%) relapsing remitting MS course converted to secondary progressive MS (SPMS), although they continued to receive GA up to 15 years. The difference from the baseline EDSS became significant starting from year 10 (Table 2). ARR was significantly associated with EDSS level at year 15 and mean increase $(\Delta)$ in EDSS score. There were significant associations between ARR at years 5 and 7, total number of relapses during 15 years and mean EDSS levels at years 11, 13, 14 and 15 (all with $p<0.05$ ). No other significant association with clinical or demographic parameters was found. Logistic regression confirmed the association between total number of relapses, ARRs at years 5 and 7 year and EDSS score at year 15 with $\mathrm{B}=1.48, \mathrm{~B}=1.87$ and $\mathrm{B}=$ 2.25 (all $p<0,01$ ). There were an association between conversion to SPMS and mean ARR during 15 years with $\mathrm{B}=1.34(p<0.05)$. No associations with baseline EDSS level, gender or age was found in this group. No

Table 2 Mean annual relapse rate (ARR) and EDSS score (mean (SD) plus intervals) changes stratified by the presence or absence of relapses or EDSS progression during the first 5 years of GA treatment

\begin{tabular}{|c|c|c|c|c|}
\hline & & $\begin{array}{l}\text { All patients } \\
(n=69)\end{array}$ & $\begin{array}{l}\text { Group A - no } \\
\text { relapses or EDSS } \\
\text { progression during } \\
\text { first } 5 \text { years of GA } \\
\text { therapy }(n=32)\end{array}$ & $\begin{array}{l}\text { Group B - with } \\
\text { relapses and/or } \\
\text { EDSS progression } \\
\text { during first } 5 \text { years } \\
\text { of GA therapy } \\
(n=37)\end{array}$ \\
\hline \multicolumn{2}{|c|}{ Age at GA start } & $33.0(0.9)$ & $31.8(1.1)$ & $34.1(1,2)$ \\
\hline \multicolumn{2}{|c|}{ Sex (females \%) } & $50(72.5)$ & $20(62.5)$ & $30(81.1)$ \\
\hline \multicolumn{2}{|c|}{$\begin{array}{l}\text { MS duration at } \\
\text { GA start, years }\end{array}$} & $5.43(0.44)$ & $5.50(0.72)$ & $5.38(0,61)$ \\
\hline \multirow[t]{2}{*}{ Baseline } & ARR & $2.15(0.06)$ & $2.05(0,08)$ & $2.24(0,09)$ \\
\hline & EDDS & $2.11(0.10) 1-5$ & $2.07(0,10)$ & $2.15(0,11)$ \\
\hline \multirow[t]{2}{*}{ Year 1} & ARR & $0.06(0.04)$ & 0 & $0.10(0.04)$ \\
\hline & EDSS & $1.93(0.09) 1-5$ & $1.92(0.14)$ & $2.03(0.12)$ \\
\hline \multirow[t]{2}{*}{ Year 2} & ARR & $0.06(0.04)$ & 0 & $0.12(0.05)$ \\
\hline & EDSS & $1.95(0.10) 1-4$ & $1.88(0.14)$ & $2.09(0.14)$ \\
\hline \multirow[t]{2}{*}{ Year 3} & ARR & $0.08(0.04)$ & 0 & $0.16(0.06)$ \\
\hline & EDSS & $2.01(0.10) 0-4$ & $1.91(0.14)$ & $2.21(0.15)$ \\
\hline \multirow[t]{2}{*}{ Year 4} & ARR & $0.13(0.04)$ & 0 & $0.22(0.07)$ \\
\hline & EDSS & $2.14(0.11) 0-4$ & $2.05(0.16)$ & $2.44(0.17)$ \\
\hline \multirow[t]{2}{*}{ Year 5} & ARR & $0.14(0.05)$ & 0 & $0.26(0.07)$ \\
\hline & EDSS & $2.19(0.12) 0-5$ & $2.02(0.16)$ & $2.53(0.17) *$ \\
\hline \multirow[t]{2}{*}{ Year 6} & ARR & $0.16(0.04)$ & $0.05(0,03)$ & $0.25(0.07) *$ \\
\hline & EDSS & $2.22(0.12) 1-5$ & $1.98(0.16)$ & $2.61(0.18) * * *$ \\
\hline \multirow[t]{2}{*}{ Year 7} & ARR & $0.17(0.05)$ & $0.06(0,03)$ & $0.30(0.07)$ * \\
\hline & EDSS & $2.27(0.13) 1-5$ & $2.00(0.16)$ & $2.70(0.18) * * *$ \\
\hline \multirow[t]{2}{*}{ Year 8} & ARR & $0.16(0.04)$ & $0.05(0,03)$ & $0.25(0.06) *$ \\
\hline & EDSS & $2.34(0.13) 1-5$ & $1.98(0.16)$ & $2.84(0.18) * * *$ \\
\hline \multirow[t]{2}{*}{ Year 9} & ARR & $0.15(0.04)$ & $0.06(0,03)$ & $0.23(0.07) *$ \\
\hline & EDSS & $2.42(0.14) 1-5$ & $1.97(0.16)$ & $3.00(0.21) * * *$ \\
\hline \multirow[t]{2}{*}{ Year 10} & ARR & $0.15(0.04)$ & $0.08(0,03)$ & $0.24(0.07)$ \\
\hline & EDSS & $2.53(0.16) 1-5.5$ ** & $2.05(0.17)$ & $3.17(0.23) * * *$ \\
\hline \multirow[t]{2}{*}{ Year 11} & ARR & $0.18(0.05)$ & $0.06(0,03)$ & $0.31(0.09) *$ \\
\hline & EDSS & $2.56(0.15) 1-5,5 * *$ & $2.00(0.15)$ & $3.20(0.22) * * *$ \\
\hline \multirow[t]{2}{*}{ Year 12} & ARR & $0.16(0.04)$ & $0.08(0,03)$ & $0.26(0.07) *$ \\
\hline & EDSS & $2.66(0.16) 1-5.5 .^{* *}$ & $2.00(0.15)$ & $3.37(0.23) * * *$ \\
\hline \multirow[t]{2}{*}{ Year 13} & ARR & $0.21(0.06)$ & $0.12(0,04)$ & $0.36(0.10) *$ \\
\hline & EDSS & $2.82(0.16) 1-6^{* *}$ & $2.09(0.14)$ & $3.59(0.23) * * *$ \\
\hline \multirow[t]{2}{*}{ Year 14} & ARR & $0.17(0.05)$ & $0.12(0,04)$ & $0.25(0.08)$ \\
\hline & EDSS & $3.03(0.16) 1-6^{* *}$ & $2.23(0.14)$ & $3.87(0.22) * * *$ \\
\hline \multirow[t]{2}{*}{ Year 15} & ARR & $0.13(0.04)$ & $0.06(0,03)$ & $0.21(0.08)$ \\
\hline & EDSS & $3.26(0.18) 1-6.5 * *$ & $2.27(0.14)$ & $4.26(0.23) * * *$ \\
\hline \multicolumn{2}{|c|}{$\begin{array}{l}\text { Mean ARR for } \\
15 \text { years }\end{array}$} & $0,15(0.05)$ & $0,07(0.03)$ & $0,22(0.06) *$ \\
\hline \multicolumn{2}{|c|}{$\begin{array}{l}\text { Mean } \Delta \text { EDSS } \\
\text { for } 15 \text { years }\end{array}$} & $1,15(0.09)$ & $0.20(0.06)$ & $2.11(0.12) *$ \\
\hline
\end{tabular}


annual relapse rate during 15 years of $\mathrm{GA}$

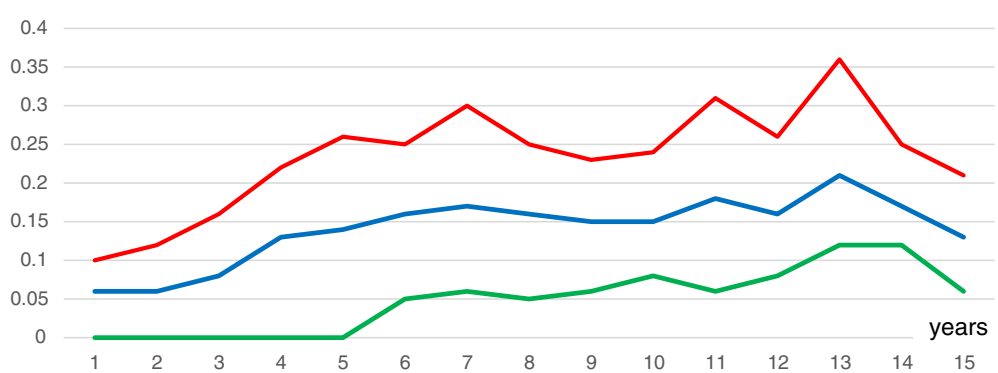

Fig. 1 Mean ARR during 15 years of GA therapy. Blue line - all patients, green - no relapses or confirmed EDSS progression during first 5 years of GA, red line - relapse and/or confirmed EDSS progression during first 5 years of the therapy

baseline demographic, clinical or MRI factors observed at the beginning of the treatment had a prognostic value for EDSS progression.

\section{Stratification analyses}

In order to assess EDSS progression after years 11-13 of GA treatment, patients were stratified into 2 groups. As the first significant association of final EDSS level at year 15 and number of relapses was found for data at year 5 , we stratified patients into 2 groups. The first, group A, includes 32 patients, 20 females $(62.5 \%)$, who had completely no relapses or disability progression during the first 5 years of GA therapy. The remaining 37 patients (30 females, $81.1 \%$ ) had at least one relapse and/or EDSS progression during these 5 years and were included into group B. The ARR and EDSS levels are presented in Table 2. There was no difference at baseline in clinical and demographic characteristics between groups $\mathrm{A}$ and $\mathrm{B}$ with the exception of a non-significant increase in females in group B. A slightly not significant increase of ARR was seen in group A at year13 and 14 (Fig. 1).
The ARRs were significantly higher in group $B$ at all time points except years 10,14 and 15. Mean ARR for 15 years in group A was significantly lower than in group B. In group A there were no significance increase in mean EDSS level comparing with baseline during these 15 years. The difference in mean EDSS between group $\mathrm{A}$ and $\mathrm{B}$ appeared at year 5 and remained significant up to year 15 (Table 2). Mean $\Delta$ EDSS for 15 years in group A was significantly lower than in group B. In group B at year 6 and later, EDSS level became significantly higher than at baseline. No single baseline demographic characteristic was associated with classification in group $\mathrm{A}$ or $\mathrm{B}$ in this subgroup of patients.

\section{Discussion and conclusions}

This 15-year observation of 69 RRMS patients under continuous GA treatment for the control of their MS in a daily practice setting demonstrated GA's longterm benefits in terms of clinical efficacy, safety and tolerability in a small majority of them and confirmed previously published data [9-12]. Thus, these patients were classified as "responders" to GA and there were no reason to change DMT [13]. However, in

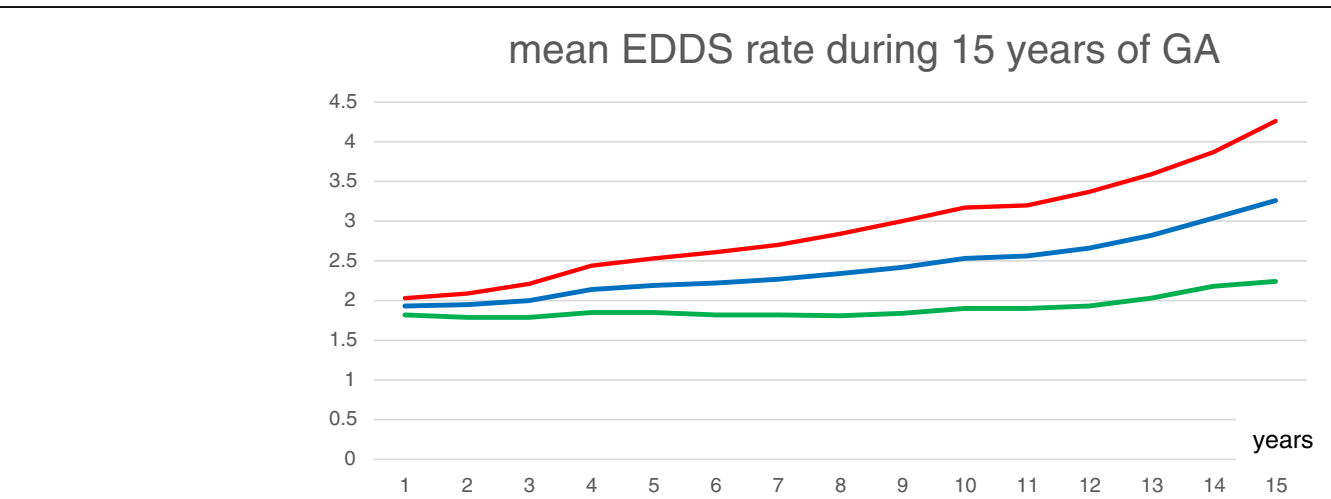

Fig. 2 Changes of Expanded Disability Status Scale (EDSS) during 15 years of GA therapy. Blue line - all patients, green - no relapses or confirmed EDSS progression during first 5 years of GA, red line - relapse and/or confirmed EDSS progression during first 5 years of the therapy 
approximately half of them the EDSS levels significantly increased between year 12 and 15, with 7 of 69 $(10.1 \%)$ converting to SPMS. These patients with "non-optimal longitudinal response" had some clinical activity, even very low, during the first 5 years of GA treatment. Thus, only total absence of clinical activity during at least 5 years of therapy might be interpreted as an "optimal" response to be maintained at long-term follow up. A recent re-evaluation of the patients from the original PRISMS study and assessed during a single follow-up visit 15 years after initial randomisation (PRISMS-15) confirmed the importance of clinical/radiological activity during the first years in longitudinal prognosis: higher dose exposure was associated with lower proportions of patients with EDSS progression and conversion to SPMS, and longer time on treatment was associated with lower risk of first relapse. Change in EDSS from baseline to 24 months was a strong predictor of evaluated clinical outcomes over 15 years [14]. While significant decrease in ARR in these patients was seen for the whole 15-year period, those who had even a low clinical MS activity had significantly worse 15-year outcome with evidence of EDSS progression and increased risk of conversion to SPMS. No association with baseline demographic, clinical or MRI characteristics was found.

In conclusion, our study is an open-label, postmarketing study with possible selection and misclassification biases, high rate of drop-outs and lacking of MRI data in which only a specific subgroup of patients with "positive" short-term response to GA was longitudinally observed. However, the study shows, that only "total" absence of clinical disease activity during the first 5 years of treatment stands as a predictor of longitudinal "optimal" response for an extended period of 15 or more years. We are not able to assess NEDA for these patients in the absence of MRI data, but since in 32 of these 69 patients no evidence of clinical disease activity was seen for 15 years, this subgroup might be classified as having the "optimal longitudinal clinical response" to GA. We suggested that in MS patients starting on GA, the presence of "disease activity" during the first years must induce to a prompt treatment change.

\footnotetext{
Acknowledgements

The authors thank all neurologists of the Department of Neurology, Neurosurgery and Clinical Genetic of the Russian State Medical University \& the MS Center (M.Davidovskaya, T.Demina, N.Khachanova, N.Lash, N.Popova, E.Popova, S, Shur, S,Zolotova) for longitudinal clinical observation of MS patients and also Professor Luigi Grimaldi for his help in manuscript preparation.
}

Competing interests

The authors declare that they have no competing interests.
Received: 28 January 2016 Accepted: 4 August 2016

Published online: 26 September 2016

\section{References}

1. Noserworthy J, Miller D, Compston A. Disease-modifying treatments in multiple sclerosis. In: Compaston A, et al, editors. McAlpine's Multiple sclerosis. 4th ed. Churchill Livingstone, Elsevier; 2006. p. 729-802

2. Giovannoni G, Turner B, Gnanapavan $S$, Offiah $C$, et al. Is it time to target no evident disease activity (NEDA) in multiple sclerosis? Mult Scler Relat Disord. 2015;4(4):329-33.

3. Rotstein DL, Healy BC, Malik MT, Chitnis T, Weiner HL. Evaluation of no evidence of disease activity in a 7-year longitudinal multiple sclerosis cohort. JAMA Neurol. 2015;72(2):152-8.

4. De Stefano N, Stromillo ML, Giorgio A, Battaglini M, Bartolozzi ML, Amato MP, Sormani MP. Long-term assessment of no evidence of disease activity in relapsing-remitting MS. Neurology. 2015;85(19):1722-3.

5. Boyko A, Davidovskaya V, Deomina T, et al. Clinical results of 3 year experience of Copaxone ${ }^{\circledast}$ in RRMS patients from the Moscow MS Center. Mult Scler. 2005;11:S82-3.

6. Boyko AN, Davidovskaya MV, Demina TL, et al. Results of the use of Copaxone and Betaferon in Moscow MS Center: analysis the clinical effects of 5-years of therapy in every day practice in Moscow MC Center. Korsakov'a J Neurol Psychiatr. 2007;4:84-94 (in Russian).

7. Boyko AN, Davydovskaya MV, Demina TL, et al. Efficacy and tolerance of glatiramer acid (Copaxone) on long-term use: 10 Years of experience at the Moscow City Multiple Sclerosis Center. Neurosci Behav Physiol. 2013:43(5): 571-6.

8. Poser CM, Paty DW, Scheinberg $L$, et al. New diagnostic criteria for multiple sclerosis: guidellines for research protocols. Ann Neurol. 1983;13:227-31.

9. Ford CC. Long-term experience with current disease-modifying drugs in multiple sclerosis. J Neurol. 2006;253 Suppl 6:vi37-44.

10. Johnson KP, Brooks BR, Ford CC, et al. Sustained clinical benefits of glatiramer acetate in relapsing multiple sclerosis patients observed for 6 years. Mult Scler. 2000;6:255-66.

11. Johnson KP, Ford CC, Lisak RP, Wolinsky JS. Neurologic consequence of delaying glatiramer acetate therapy for multiple sclerosis: 8-year data. Acta Neurol Scand. 2005;111:42-7.

12. Wolinsky JS, Narayana PA, Johnson KP, et al. United States open-label glatiramer acetate extension trial for relapsing multiple sclerosis: MRI and clinical correlates. Mult Scler. 2001;7:33-41.

13. Karussis D, Biermann LD, Bohlega $S$, et al. A recommended treatment algorithm in relapsing multiple sclerosis: report of an international consensus meeting. Europ J Neurol. 2006;13:61-71.

14. Kappos L, Kuhle J, Multanen J, et al. Factors influencing long-term outcomes in relapsing-remitting multiple sclerosis: PRISMS-15. J Neurol Neurosurg Psychiatry. 2015;86(11):1202-7.

Submit your next manuscript to BioMed Central and we will help you at every step:

- We accept pre-submission inquiries

- Our selector tool helps you to find the most relevant journal

- We provide round the clock customer support

- Convenient online submission

- Thorough peer review

- Inclusion in PubMed and all major indexing services

- Maximum visibility for your research 